\title{
Continuous Process Improvement in Banking Sector and a Model Design for Performance Enhancement
}

\author{
Lixia Wang (Corresponding author) \\ School of Management, Shanghai University \\ 99 Shangda Road, Shanghai 200444, China \\ E-mail: lilywlx@hotmail.com \\ Drama Bedi Guy Herve \\ School of Economics, Shanghai University \\ 99 Shangda Road, Shanghai 200444, China \\ Yao Shen \\ School of Economics, Shanghai University \\ 99 Shangda Road, Shanghai 200444, China
}

Received: June 29, 2011

Accepted: August 22, $2011 \quad$ Published: January 16, 2012

doi:10.5539/ijbm.v7n2p130

URL: http://dx.doi.org/10.5539/ijbm.v7n2p130

\begin{abstract}
The purpose of this study is to analyze the design and implementation of CPI in the bank, to identify the benefits and develop a better understanding of CPI impact on banking competitiveness, to build processing bank system (PBS) effectively. The study analyzed and improved the CPI theoretical from some aspect of the core ideas, theoretical system, and its applications. Then it proposed a conceptual model of process improvement: CPI-PBS hybrid deployment model. LSS was applied as the main tool of CPI to build PBS dynamic optimization system and provided an empirical example of how CPI constitutes better performance. Through analysis, the research drew some conclusions as below. 1, the application of CPI theory to service industries has a good effect, but it should seriously consider the applicability and feasibility. 2, the process improvement in commercial banks is a dynamic, continuous forward process, and it can get a good synergy effect that the strategic integration of CPI theory and PBS thinking. 3, to realize the strategic goal of PBS, LSS alone was not enough. It should integrate the concept, model system of CPI with the theory and methodology of LSS. Then it found out the difficulties and countermeasures of application of CPI to management banks.
\end{abstract}

Keywords: CPI, PBS, LSS, Process improvement

\section{Introduction}

The global economy and finance tend to integrations. It is the trend of the Chinese integration into world financial markets. The era of post-economic crisis will be a "Heated Rivalry" era which is based on the global economy and high-tech as the core elements. The banking sector was hit firstly since the U.S. sub prime mortgage crisis had happened, and this crisis sounded the alarm to the banking sector. Then, it is an inevitable choice to establish international banking management model and continue to enhance the core competitiveness (Shleifer, 2009). Processing Bank System (PBS) is a kind of widely used management model for many international advances bank. Since 2006, banking industry of China began to explore the building of PBS, although they made some progress and effect. From the aspects of strategic deployment and specific operational processes, how to effectively promote the construction of PBS was an urgent problem.

In order to realize PBS effectively, the commercial banks require Continuous Process Improvement (CPI) to conform to the current financial deepening and the international trend, so as to enhance their core competitiveness. Because, its core of management to build PBS should gradually transform to the management strategy that is strategic core business, organizational change and the pursuit of quality and efficiency. The theory of CPI is a kind of philosophy and methodology that guided the organization to think comprehensively 
and improve process effectively. CPI is a theory which based on customer satisfaction-oriented, and it applied all kinds of tools to realize systematic management. So, to commercial banks, the need of CPI is from not only the external environment changes and also from their own internal needs.

CPI is a proven efficient methodology in Department of Defense (DOD) (Person, 2007) and it has been adopted successfully in the management of all types of processes to manage the rapid changes in our global environment (Componation and Farrington, 2000; Ferguson et al., 2007; Friesner et al., 2009; Han et al., 2008; Kalb and Masson, 2002; Lewis, 1999; Linnean III, 2007; Malheiros et al., 2008; Person, 2007; Plamer and Ingrassia, 2005). But when we surveyed the application of CPI theory, we found that most research usually focused on the military affairs or medical problems, and it seldom discussed business performance from the viewpoint of the service industry, especially in banking services, which is the most critical topic in service operations. Service operations now comprise more than $70 \%$ of the GDP in China and are rapidly growing around the world, and banking services are the most critical concern in the service industry. This study filled these gaps.

Base on the background, this research analyzed Chinese commercial banks how to build PBS in view of CPI and by structured approach.

The main objectives of this study are given as follows. We view the main theory of CPI, Lean Six Sigma (LSS), processing Bank System (PBS), and described their relationship. Then, we illustrate similarities and differences between the CPI and LSS according their evaluation. The research explores the development of domestic and foreign commercial banks PBS. It analyzes and improves the CPI theoretical from some aspect of the core ideas, theoretical system, application tools and procedures. Then, the paper combines the theory of CPI and the think of PBS to propose a conceptual model: CPI--PBS hybrid deployment model. It uses the methodology of LSS as the main application tool of CPI theory. Between the macro level and micro level in the CPI--PBS hybrid deployment model, and utilizes key performance indicators (KPI) as the control node. Through comparison and analysis, the study implements a process improvement model which is suitable to commercial banking system. Eventually, it can truly achieve the goal of modern commercial banks. This research discussed the construction of PBS from two levels of strategic deployment and financial practices and by the case from Bank C; we can get more good experience and prove its feasibility and validation. Then, it investigated how to gradually strength the various departments operation and enhance internal control mechanisms of the banking sector. It analyzed the applicability and feasibility of the application CPI to build and develop PBS. Then found out the difficulties and countermeasures of application of CPI to management banks. The remain part of paper is divided as follow. Section 2 involves the literature review, developing a Deployment Model of PBS is depicted in section 3. The section 4 deals with the case study and the last section is the concluding part and highlights some recommendations.

\section{Literature Review}

\subsection{CPI and Its Application}

Quality is a never ending quest and CPI is a never ending effort to discover and eliminate the main causes of problems (Lake, 2003). CPI is a system approach that requires the holistic integration of all improvement activities to accomplish operational objectives. CPI guide the organization thinking revolution and process optimization, which is based on customer satisfaction leaning, with many CPI tool to realize all kinds of systemic management, such as innovative thinking, drawing process diagrams, flowcharts, knowledge discovery tool etc. (Vance, 2009; Ferguson et al., 2007).

CPI is a strategic approach for developing a sustainable improvement culture in the area of quality, productivity, service, decision making processes and innovation processes. CPI is also a strategy for increasing companies' sustainable competitive advantages and promoting innovation, cost leadership, product differentiation, and resource continuous improvement (Ward, 1994). When we engage in process improvement, we seek to learn what causes things to happen and then use this knowledge to reduce variations, remove activities that have no value to the organization and improve customer satisfaction (Gijo \& Perumallu, 2003). The core principle of CPI is the self reflection of processes. That is a process of feedback (Lake, 2003). The purpose of CPI is the identification, reduction, and elimination of suboptimal processes. That is to make the process more efficient. The emphasis of CPI is on incremental, continuous steps, avoiding quantum leaps. It is a kind of evolution (Vance, 2009). The elements above are the more tactical elements of CPI (Bice, 1989). The more strategic elements include deciding how to increase the value of the delivery process output to the customer and how much flexibility is valuable in the process to meet changing needs (Han et al., 2009).

Some researchers described CPI as a meta-process for most management systems, such as Business Process Management, Quality Management, and Project Management (Malheiros et al., 2008). Deming (1986) saw it as part of the 'system' whereby feedback from the process and customer were evaluated against organizational goals. 
The fact that it can be called a management process does not mean that it needs to be executed by 'management' merely that it makes decisions about the implementation of the delivery process and the design of the delivery process itself (Malheiros et al., 2008). There are many approaches to realize CPI (Lake, 2003; Wadsworth, 2001). Most aim for small improvements rather than large-scale change and strive to eliminate activities that have no value. CPI is important for workplaces because Pareto's Principle (the 80/20 rule) applies. It is said that processes account for $80 \%$ of all problems while people account for the remaining $20 \%$ (Componation and Farrington, 2000; Plamer \& Ingrassia, 2005).

CPI focuses on the following four key elements that require a common understanding and support to facilitate ongoing CPI initiatives and set the stage for greater enterprise-level improvement. Firstly, it is a broad-based, structured CPI implementation method that spotlight why a sound plan is needed and how to determine and implement the best solution. Secondly, it is a focus on CPI implementation within a structure of goals that are aligned to a war-fighter-driven, outcome-based metric. Thirdly, it emphasize on the management and integration of CPI projects. Last but not least, it is a ways to determine how well projects and organizations are progressing with CPI initiatives, training and certification. Continuous improvement is an ongoing effort to improve products, services or processes. These efforts can seek "incremental" improvement over time or "breakthrough" improvement all at once (Kalb \& Masson, 2002). There are dozens of examples of how the application of CPI techniques has translated into significant productivity gains, lower costs, and reduced cycle times (Ferguson et al., 2007; Starks, 2009; Malheiros et al., 2008). CPI is a proven methodology and has been adopted successfully in the management of all types of processes to manage the rapid changes in our global environment. In Department of Defense (DoD), CPI comprises the application of a broad range of tools and methods, such as Lean, Six Sigma, and Theory of Constrains (TOC).

CPI in DoD is a strategic approach for development a culture of continuous improvement in the area of reliability, process cycle times, costs in terms of less total resource consumption, quality, and productivity (Person, 2007). Much of what People do within the DOD is guided by process. They have an acquisition process for developing and acquiring their defense systems, processes for overhauling equipment, processes for submitting travel claims, and so on. Consequently, the effectiveness, quality, and efficiency of our work are very much driven by the processes we use to do our job (Hammer, 1990). CPI provides methods, tools and philosophies that can be used to improve the way we work. It is applied on a never-ending basis, resulting in greater efficiency end effectiveness. DOD is now adopting these best practices and absorbing the lessons learned from these isolated pockets of CPI success (Linnean III, 2007). The result is a strategic approach to developing a department-wide culture of continuous improvement in the areas of reliability, process cycle time reductions, costs, quality, and productivity (Person, 2007; Wardsworth et al., 2001).

CPI has proven to be an important tool for improving the operating effectiveness in the DOD. For example, the Air Force applied CPI to improve its medical referral management process and reduced the flow time on provider authorizations from 97 hours to 1 hour. The Army used a Lean approach to increase the mean time between overhaul for T700 helicopter engines by 300 percent. The Navy reduced the cycle time for F404 jet engines by 78 percent in two years. The Marine Corps applied TOC tools to reduce the repair cycle time for CH-46 helicopters by 40 percent. These successes, and many others like them, demonstrate CPI's ability to apply world-class, best-of-breed practices to meet a wide range of operational requirements.

These good experiences set the stage for greater enterprise-level improvement. CPI focuses on making each process as efficient as possible. The theory, also called Kaizen, is focused on the cumulative effect of many small improvements. Kaizen is driven by spontaneous, bottom up change (Bond, 1999; Vance, 2009). No one knows a production, administrative or operating department like those working in it every day. Some published reports indicate this incremental approach can result in a $100 \%$ increase in efficiency over the period of 12-18 months (Kalb \& Masson, 2002; Han et al., 2008). However, improvement will vary from company to company in part dictated by how inefficient a company was at the time restructuring began. Investments in CPI are usually small due to the incremental nature of changes.

\subsection{CPI and PBS}

To commercial banks, the need of CPI is from not only the external environment changes and also from their own internal needs. The banking sector suffered the primary brunt of the American sub-prime mortgage crisis. Chinese commercial banks face extremely fierce competition in domestic and foreign markets. As a service industry, the commercial bank faced the gradually fierce market competition and customer market maturing. In particular, for people to the pursuit of product and service quality is increasingly demanding. To build PBS, its core of management should gradually transform to the management strategy that is strategic core business, organizational change and the pursuit of quality and efficiency. The theory of CPI is a kind of philosophy and methodology that guided the organization to think comprehensively and improve process effectively. So, in order 
to realize PBS in China, we need CPI to conform to the current financial deepening and the international trend, to focus on customer, to actively respond to the concept of market competition, to enhance their core competitiveness (Küng \& Hagen, 2007).

The Processing Bank System (PBS) refers to a commercial bank management model. It is a kind of widely used management model for many international advances bank. This management model is customer-focused, market-oriented, emphasizing the main business lines within the system of marketing, management and accounting. According to Deloitte's definition, PBS is the bank's services from quality, cost, time, risk and regulations to implement the five principles to front, middle and background processes. Moreover, in order to balance these five principles, the bank can not be too fast in time to ignore risk prevention. So, PBS should base on department responsibility. The operation of PBS stress the vertical management on line of different business and stress centralization dealing with the business of accounting, billing, monitoring and customer relationship management etc., a large number of middle and background business.

The essence of PBS is, to change its traditional operating mechanism, and to build a new banking model which is focus on customer, with IT technology support, with the main features to organizational innovation and process improvement, change and reengineering, with resource integration in all domains. PBS embodies the modern bank's flexible capacity and competitiveness by level flat, clear responsibilities and rights, team unity to adapt to rapidly changing market.

How to build a PBS effectively? Then, we have to mention Business Process Reengineer (BPR). The classic definition of BPR given in Hammer and Champy's (1993) pioneering book--Reengineering the Corporation: A Manifest for Business Revolution. They defined BPR as it's clear that BPR is an ongoing iterative process and itself requiring strong commitment and vision from senior management. This kind of incremental changes to build PBS include four steps, namely, process identification, homing, improvement and reengineering (China Economic Net, 2008).

\subsection{LSS and PBS}

Lean Six Sigma (LSS) is the perfect combination of lean production and six sigma theory. CPI, as applied in DOD, is based on three complementary but distinct viewpoints--Lean, Six Sigma and TOC (Person, 2007, Ehie \& Sheu, 2005). As the main tool of CPI theory, Lean Six Sigma (LSS) has been widely used and developed in the management of all types of processes (Snee, 2010; Pojasek, 2003; Brewer, 2009; George, 2003). As we know that with extensive modification, early adopters of Lean Six Sigma for financial services, such as Bank of America, Merrill Lynch, and Vanguard, have leveraged the power of this methodology to create billions of dollars in operational cost cuts and up to 25 -percent improved customer service rates. This management approach has four essential factors: (1) Delight your customers with speed and quality, (2) continuously improve your processes, (3) work together for maximum gain, (4) base decision on data and facts (George, 2003; Nonthaleerak \& Hendry, 2006).

LSS integrate lean manufacturing and six sigma, absorbing the advantages of two management models, to make up for lack of a single management model to achieve "1+1>2" synergy and achieve the best effect of management. As a management philosophy, LSS focus on customer satisfaction and its operation emphasis on standardized processes, reduce volatility to balance and optimize the interests of all (George et al., 2004; Zu et al., 2008). LSS pay attention to the critical success factors (CSF) that is to focus on the system, emphasis on cultural development, centralize on process, leadership support, and choose the right person, right way and instrument (Coronado \& Antony, 2002). So it becomes a powerful support tool to CPI theory (Pajasek, 2003; Linderman et al., 2006).

LSS is an improvement methodology based process (Goldratt et al., 2009). An organization's operational performance depends upon its' core processes performance. Banks attach greater importance to processes, which is the "manufacturing" in financial sector. In fact, the essence of management of commercial banks lies in their better process management (George, 2003; Allen, 2006). PBS is just an organizational form making process as a management starting point; meanwhile it means that its system construction and operating mechanism will also be launch from process as a blueprint for work (Allen, 2006). Accordingly, LSS would be a strong support to build PBS. All of the financial industry closely link with process. To explore development of PBS in the domestic and foreign bank, the bank of America applies initiatively Six Sigma methodology as the key management tool to bank services industry. Currently, Six Sigma management has become an effective strategy to improve domestic banks, such as China Merchants Bank, China Construction Bank, Min Sheng Bank, Industrial Bank, Shanghai PuDong Development Bank. They all have launched a large-scale practice by using of VOC-driven process change method to construct PBS and made useful references (SBTI team, 2009).

In Bank, the business operations have a strong regularity, repeatability, and relatively more standardized 
transaction processes (Yuan et al., 2008). These characteristics are very suitable for LSS thinking and approach to improve business processes. No matter to what extent the development of information technology is in an enterprise. Machinery or computer can't completely replace the service personnel to provide services to customers. LSS make decision by data, while the massive financial transaction data and highly information-oriented acquisition system to get real-time data create a unique condition for "making decision by data" (Hayler \& Nichols, 2007). Accordingly, LSS thinking and methodology will be very helpful during the evolution to build PBS in China.

LSS methodology in process management hold that, for a typical PBS, its value chain should mainly contain a overall closed-loop process, from product in chain to customer value source management (Hines \& Rich, 1997), as indicated in Figure 1. Unlike the usual sense of the value chain, the biggest difference of PBS's value chain is that it's a closed loop process. The value source, which comes from customer value group, is not only the end of the entire value chain, but also the power of some process and links which drives the whole bank operations from product development to the channel promotion. So the model of the whole value chain of PBS can be summarized as: ACFC ("At Customer. For Customer."). At Customer refers to standing customer's perspective, and For Customer is consideration whether a bank can achieve the true customer value through its own products, IT system of operation and maintenance, marketing, channel management et al. Therefore, Value obtain of PBS, even the driving force of process change, comes from Voice of the Customer (VOC). It can be said, who understand customers, will win the market (SBTI team, 2009).

\section{Developing a Deployment Model of PBS}

Operations are viewed in the context of customer expectations and requirements, operational environments, resource requirements, and technology. The underlying CPI concepts are put into practice through a disciplined CPI deployment approach that should change how we view and think about work. It provides a customer satisfaction focus that is value-driven, not task driven, with value being defined by the customer. The purpose of PBS is to meet the needs of customers and enhance core competence. The Chinese commercial banks need CPI to realize its core competitiveness. Banking business operations have a very strong regularity, repeatability, and relatively more standardized transaction process. These characteristics are very suitable for LSS thinking and approach to realize business process Improvement (George, 1992; Küng \& Hagen, 2007). Figure 2 illustrates two processes (planning and implementation) and every step in the CPI-PBS hybrid deployment model. The CPI-PBS deployment planning and implementation processes are complementary. Just as CPI-PBS implementation is guided by deployment planning, results from implementation are fed back into the planning cycle.

\subsection{The first process of the model}

The first process of CPI--PBS Hybrid Deployment model is planning. Like many models, the CPI deployment cycle begins with the development of CPI mission and vision statements and is complemented by a strategic plan on how to make the vision a reality. A focused mission, a clearly articulated vision, and well-strategic plan provide the framework to achieve the organization's objectives. Five important factors could help to realize them. 1. Common vision and marching orders that foster teamwork, inter-departmental cooperation and alignment between goals, metrics and actions. 2. Focus on reducing constraints to achieve better utilization of resources and capability. 3. Continued acceleration of improvement efforts. 4. Better foundation for fact-based analysis and decision-making. 5. Expanding perspective on the entire (end-to-end) value stream.

The CPI mission is a concise, unambiguous, and measurable description of the organization's role in the overall objectives. The CPI vision is a view into the future that succinctly describes how the organization will conduct business. It implies a gap between the current state and a better future state. The strategic plan provides the high-level actions to be taken over the timeline of the plan to make the Vision a reality. The purpose is to portray a comprehensive, integrated roadmap for an organization that supports its goals for completing its mission. The strategic plan must be a living document that is formally redrawn based upon the environment in which the organization operates.

Borrowing a key tool from the Lean philosophy, the second step of the deployment model calls for the development of a value stream map and conducting the associated analysis. A value stream encompasses all the planning, execution, products, and services that go into a process to create value for a customer. With the mission, vision, and strategic plan in place and communicated to the workforce, the first task is to align the processes to support that direction. The best way is through a value stream mapping process that helps illustrate the opportunities for improvement. Value stream mapping and analysis must focus on value to the customer and typically includes development of a current state map which describes the existing process and uncovers improvement opportunities, and a future state map that the describes the desired future process vision and 
through gap analysis reveals potential leverage points for process improvement. Typically, an organization's value stream mapping activities will also involve the identification and analysis of both the "value added" and "non-value added" time in the process. A value stream map captures all the actions currently required to deliver a product or service to the customer, and only through using a value stream map to first document how we currently do our jobs, can we identify those processes or activities that add no value to our customer (Hine \& Rich, 1997). Value stream analysis helps guide the sequencing of efforts in addressing process inefficiencies with effective CPI projects. The value stream analysis is conducted at multiple levels within an enterprise and is usually better accomplished as a top down activity.

The third step of the deployment model, "develop structure and behavior", creates an organizational structure and training certification program to successfully institutionalize CPI within an organization (Sterman et al., 1997). Successful mission completion on a reliable and cost-wise basis depends on the development of an effective supporting infrastructure. The success of any initiative is dependent upon strong leadership (Klein \& Sorra, 1996).

Led by a CPI champion and guided by a CPI steering committee, a CPI support team provides CPI training and facilitates the management of CPI initiatives, work groups conducts every step specifically, and peer group should also be used to strengthen performance, as appropriate. Within this framework, the Champion articulates the core values and sets the top-level expectations in terms of the enterprise's mission and vision. The champion needs to insure a connection with all elements of the enterprise regarding what CPI means and what must be done. The champion must slice through organizational barriers and filters to insure these connections are made and continued, such as in the example of champion sponsored town hall meetings in General Electric. The steering committee is the champion's main vehicle for keeping the CPI efforts aligned with expectations. The CPI support team provides the technical expertise and consistency of approach. This enables CPI to become a repeatable process that is engrained in the behavior and language of the organization and ultimately becomes a defining element of its culture. The CPI working group accomplishes the detailed analysis of current operations, obtains the input of peer groups when appropriate, and develops options for improvements. Peer groups operate within and across functional areas to share experiences, best practices, and benchmarks. The hierarchy is completed with the establishment of CPI peer groups, which provide for mutual support and the sharing of CPI information across the organization, and seek ways to smartly optimize results across many processes.

The fourth step in CPI-PBS deployment is the alignment and deployment of goals. One of the key elements in moving an organization forward in a coordinated manner is through the alignment and deployment of goals. Goals established for an organization must support and be consistent with the goals of its higher level commands. There should be a clear link between the goals of a major command and those of its reporting sub-units. It is essential that progress toward goal accomplishment be formally measured and visible. Metrics should be outcome based as a tool for daily operations and aligned with the organization's goals. These goals need to be quantified through thoughtfully developed metrics. These metrics will guide behavior on a daily basis as an organization pursues its mission. There needs to be a direct, identifiable, casual relationship between each metrics and one or more goals. CPI efforts should be selected and implement in alignment with organizational goals and strive to have the greatest possible effect on the value stream.

\subsection{The second process of the model}

The second process of CPI-PBS hybrid deployment cycle is implementation. Once the foundation of CPI deployment has been established with the four planning activities, the next phase is implementation phase guided by LSS methodology, which composed of five phases each, bear the acronyms DMAIC. The DMAIC project methodology has five phases:

Define the problem, the voice of the customer and the project goals.

Measure key aspects of the current process and collect relevant data.

Analyze the data to investigate and verify cause-and-effect relationships. Determine what the relationships are, and attempt to ensure that all factors have been considered. Seek out root cause of the defect under investigation.

Improve or optimize the current process based upon data analysis using techniques such as DOE (Design of Experiments), poka yoke or mistake proofing, and standard work to create a new, future state process (He et al., 2009). Set up pilot runs to establish process capability.

Control the future state process to ensure that any deviations from target are corrected before they result in defects. Control systems are implemented such as SPC (Statistical Process Control), production boards, and visual workplaces and the process is continuously monitored.

In executing the approved operational plan, teams are first identified, managed, and trained on CPI techniques. 
Using LSS approaches, targeted processes are based on using value stream maps. Then, by applying LSS classic process-DMAIC, progress against the operational plan is monitored using the previously agreed-upon metrics and reported to stakeholders. CPI should be a basic strategy for accomplishing the specific operational steps. CPI enhances current practices by capturing and standardizing the positive results achieved by the staffs. Feedback via coaching from peers, support teams, steering committees, and CPI champions is used to improve results.

\subsection{Reentry and KPI}

Periodically, the overall process should be revisited to check whether the organization is moving toward the end state expressed by the mission and vision and captured in the strategic plan. This requires returning to the beginning and revisiting the mission, vision, and strategic planning steps. Between the macro level (the first process) and micro level (the second process) in the above deployment model, the research used key performance indicators (KPI) as the control node. As figure 2 depict the process conduct re-entry with the KPI. KPI are the important indictors to measure whether the process improvement in banks can improve performance. Meanwhile, the KPI indicators are used to guide implementation of organizational strategy, and the system of KPI indicators is the early warning system for organizational strategy and plan deviations. All the steps should be revisited in the same disciplined way to ensure that the organization is moving in the right direction. This feedback serves ad the basis for subsequent planning activities as the never-ending continuous improvement process continues (Person, 2007).

\section{A Case Study}

Basic situation in this case: there are seven windows serviced by staff in Bank $\mathrm{C}$, and only three to five windows in use, usually. But customers seldom use ATM, which more than ten. So long queue often appears in windows serviced by staff. Figure 3 illustrates the service time of twenty seven customers, and we can count that the average service time is 104 second. We analyze the data (service time of twenty seven customers one day) from Bank C, and draw conclusion below. Average arrival rates every customer: about 132 people per hour, it submits Poisson distribution. Average service rates every window: about 35 people per hour, it submits Exponential Distribution. There are three windows in service. There are fewer customers near 13:30, but quickly quantity adds mostly. Approximately at 13:50, there add a window, that is, four windows in service at that time. Near 14:10 there add a window, again.

\subsection{Process of D-M-A-I-C}

\subsubsection{Define}

Problem description: the average service time is 104 second in Bank $\mathrm{C}$ which has a high rate of queue, and there's long distance between customer's expectation and satisfaction. If Bank $\mathrm{C}$ didn't improve efficiency, the customer would go to other bank.

Aim description: improve the service efficiency, and make the service quantity increase to 60 persons per hour. Draw SIPOC diagram (a tool used to identify and categorize the parts of a process as relating to either the suppliers, inputs, process, outputs, or customers), according to service process, we can draw the service system flow diagram of Bank C (figure 4).

\subsubsection{Measure}

In the stage of measuring, we should measure the time of each step and study out plan about data collection and sample gathering, gauge the data of appraisal system needed. We can draw a conclusion that there is a direct relationship between queue problem of savings bank and quantity of service window, service time of each customer.

\subsubsection{Analyze}

Within the main step of service process, by calculation, we find the service time and service window are strongly influential with queue quantity. From table 1, we can see that the queue system of Bank C is irrational. Because from the data of first line, the probability of customer who must wait to queue when arrived system is $94.3 \%$, the average number of queue customer is near 15.6 people, the average queue time of every customer is 0.4714 hours (28.3 minutes) which is 16 times more than average service time (104 second). Moreover, the probability of at least 7 customers in system is $66.3 \%$. Really it is irrational to customer. When facing so fierce competition, bank $\mathrm{C}$ should improve efficiency to increase service quality. Commonly, there are two measures to realize it. One way is to increase service window. Secondly, reduce service time. Now we will analyze the two ways below.

If we adopt the first way, increasing service window, queue standard is the same, it is like making customer detour. The service rate of each system is still 35 persons per hour. You can see the result from the second line of table 1 . 
If we adopt second way, not increasing service window, but we can increase counting money machine and establish management information system of customer etc. to reduce service time of each business, to make the service quantity increase from 35 to 60 persons per hour.

You can see the result from the third line of table 1 that the average queue time of every customer reduce from 0.4714 hour to 0.0204 and the average stayed time every customer reduce from to 0.5 hour to 0.0371 hour. At the same, the probability of at least 7 customers in system decrease deeply from $66.3 \%$ to $1.49 \%$.

So the result of system improvement and decreasing service time is better than increasing service window. Time analysis: reducing service time make quantity of customer in system decrease largely, and since customer quantity add from 35 to 60 persons, the probability that at least 7 customers in system reduce to $1.49 \%$.

\subsubsection{Improve}

According to the design of the stag of analysis, we can use two methods to reduce service time, that is increasing new-style counter machine and establish MIS of customer. Other measure can be taking simultaneously to realize the aim, such as increasing service window and waiting for service by queue machine, take plenty advantage of system resources etc.

\subsubsection{Control}

We make the improved measures included in the daily management, then establish performance evaluation standard in order to maintain the improved performance and prevent rebound.

Through systematic analysis of bank service, we can see significant improvement in performance after the implementation of LSS project. Service efficiency has been enhanced, and the bank competitiveness has been strengthened. Accordingly we completed a LSS project, and constantly looking for new project.

Then how to make it continuous dynamically improved? First of all, we should define a key performance index (KPI) to make it a controlling point according to the bank's needs. Each time meet problem-- not meets the KPI needs-- then operates the LSS project again.

\section{Conclusion}

The process improvement in commercial banks is a dynamic, continuous forward process. As a very mature international banking model, PBS is a good management model for China to build modern commercial bank. The realize PBS effectively, it required not only systematic thinking in strategic level, but also effective operation way in implementation level. CPI is a proven methodology and has been adopted successfully in the management of all types of processes to manage the rapid changes in our global environment. In order to realize PBS, Chinese commercial banks need CPI to conform to the current financial deepening and the international trend, so as to enhance their core competitiveness. As the main tool of CPI theory, LSS has been widely used and developed in the management of all types of processes. Banking sector attach greater importance to processes. PBS is just an organizational form making process as a management starting point. So LSS methodology would be a strong support to build PBS. Based on the analysis of the Chinese commercial banks' current situation and existing problems, the article established a conceptual model of process improvement: CPI--PBS hybrid deployment model, and applied LSS as the main tool to build process bank dynamic optimization system. At the same time it did a theoretical validation of this method. By the case from Bank C, we can get more good experience and prove its feasibility and validation, meanwhile to make a foreshadowing for this kind of research.

Through analysis, the research drew conclusions as below. 1, the application of CPI theory to service industries has a good effect, but it should seriously consider the applicability and feasibility. 2, PBS is a good management model for China to build modern commercial bank. 3, the alliance philosophy and methodology of CPI with PBS can achieve the best synergy effect of management. 4, LSS is a strong operational way to construct PBS dynamic optimization system.5, to effectively realize PBS, LSS alone was not enough. It should integrate the concept, model system of CPI with the theory and methodology of LSS. Through compare and analysis, the study proposed a process improvement model which is suitable to Chinese commercial banks and found out the difficulties and countermeasures of application of CPI to management banks.

\section{References}

Allen, P. H. (2006). Reengineering the Bank: A Blueprint for Survival Success. McGraw Hill.

Anand, G., Ward, P. T., \& Tatikonda, M. V. et al. (2009). Dynamic capabilities through continuous improvement infrastructure. Journal of Operations Management, 27: 444-461. http://dx.doi.org/10.1016/j.jom.2009.02.002

Anand, R. B., Shukla, S. K., Ghorpade, A., Tiwari, M. K., \& Shankar, R. (2007). Six sigma-based approach to optimize deep drawing operation variables. International Journal of Production Research, 45(10): 2365-2385. http://dx.doi.org/10.1080/00207540600702308 
Bice, A. E. (1989). Three steps to continuous improvement. 43rd Annual Quality Congress Transactions, 43: 800-805.

Bond, T. C. (1999). The role of performance measurement in continuous improvement. International Journal of Operation Product Management, 19(12): 1318-1334. http://dx.doi.org/10.1108/01443579910294291

Brewer, J. (2009). Looking Forward Using Lean Six Sigma in Navy Assistance: The next step. The DISAM Journal, 21-23.

China Economic Net. (2008). Four step to build Processing Bank. [Online] Available: http://os.manaren.com/jgsj/200811/895.html

Componation, P. J., \& Farrington, P. A. (2000). Identification of effective problem-solving tools to support continuous process improvement teams. Engineering management journal, 12(1): 23-29.

Coronado, R. B., \& Antony, J. (2002). Critical Success Factors for the successful implementation of Six Sigma projects in organizations. The TQM Magazine, 14(2): 92-99. http://dx.doi.org/10.1108/09544780210416702

Dannenberg, M., \& Kellner, D. (1998). The Bank of Tomorrow with Today's Technology. International Journal of Bank Marketing, 16(2): 90-97. http://dx.doi.org/10.1108/02652329810206743

Deming, W. E. (1986). Out of the Crisis. Massachusetts Inst Technology.

Ehie, I., \& Sheu, C. (2005). Integrating six sigma and theory of constraints for continuous improvement: a case study. Journal of manufacturing technology management, 16(5): 542-553. http://dx.doi.org/10.1108/17410380510600518

Ferguson, D., George, S., \& Huyck, M. (2007). Work in process -Continuous Process Improvement in Attainment of Learning Objectives. $37^{\text {th }}$ ASEE/IEE Frontiers in Education Conference.

Friesner, D., Neufelder, D., \& Raisor, J., et al. (2009). How to Improve Patient Satisfaction when patients are already satisfied: a continuous process improvement approach. Hospital Topics, 87(1):24-40. http://dx.doi.org/10.3200/HTPS.87.1.24-40

George, B. M. (1992). Reengineering financial processes. Bankers Magazine, 175(4):42-45.

George, M. L. (2003). Lean Six Sigma for Service. The McGraw-Hill Companies.

George, M., Rowlands, D., \& Kastle, B. (2004). What Is Lean Six Sigma? The McGraw-Hill Co.

Gijo, E. V., \& Perumallu, P. K. (2003). Quality improvement by reducing variation: A case study. TQM \& Business excellence, 14(9): 1023-1031.

Goh, T. N., Low, P. C., Tsui, K. L., \& Xie, M. (2003). Impact of Six Sigma implementation on stock price performance. TQM and Business Excellence, 14(7): 753-763. http://dx.doi.org/10.1080/1478336032000090969

Goldratt, E. M., \& Cox, J. (2009). The Goal. North River Press.

Hahn, G. J., Hill, W. J., \& Hoerl, r. W. et al. (1999). The impact of Six Sigma improvement - a glimpse into the future of statistics. American Statistical Association, 53(3): 208-215.

Hammer, M. (1990). Reengineering work: Don’t automate, obliterate. Harvard Business Review, July-August: $18-25$.

Hammer, M. (2002). Process management and the future of Six Sigma. Sloan Management Review, 43(2): 26-32.

Hammer, M., \& Champy, J. (1993). Reengineering the Corporation: A Manifest for Business Revolution. New York: NY HarperCollins.

Han, K. H., Park, J. W., \& Jo, Y. H. (2008). Process-Centered Knowledge Model for Continuous Process Improvement. Proceedings of the 2008 IEEE IEEM, 42-46.

Hayler, R., \& Nichols, M. (2007). Six Sigma for Financial Services: How Leading Companies Are Driving results with Lean, Six Sigma and Process Management. The McGraw-Hill Companies.

He, Z., Han, Y. J., \& Shuang, Z., et al. (2009). Product and process optimization design through Design of Experiments: A case study. Total Quality Management, 20(1): 107-113. http://dx.doi.org/10.1080/14783360802614315

Hines, P., \& Rich, N. (1997). The seven value stream mapping tools. International Journal of Operation and Product Management, 17(01): 46-64. http://dx.doi.org/10.1108/01443579710157989

Kalb, G. E., \& Masson, G. M. (2002). Continuous Process Improvement and the Risk to Information Assurance. IEEE Software, 84-86. http://dx.doi.org/10.1109/52.976945 
Klein, K. J., \& Sorra, J. S. (1996). The challenge of innovation implementation. Academy of Management Review, 21(4): 1055-1080.

Küng, P., \& Hagen, C. (2007). The fruits of Business Process Management: an experience report from a Swiss bank. Business Process Management Journal, 13(4): 477-487. http://dx.doi.org/10.1108/14637150710763522

Lake, E. (2003). Course Development Cycle Time: A Framework for Continuous process improvement. Innovative higher education, 28(1):21-33. http://dx.doi.org/10.1023/A:1025411517749

Lewis, N. D.C. (1999). Continuous process improvement using Bayesian Belief Networks. Computers and Industrial Engineering, 37: 449-452. http://dx.doi.org/10.1016/S0360-8352(99)00115-1

Linderman, K., Schroeder, R. G., \& Choo, A. S. (2006). Six Sigma The role of goals in improvement teams. Journal of Operations Management, 24: 779-790. http://dx.doi.org/10.1016/j.jom.2005.08.005

Linnean III, H. W. (2007). AFO21: Identifying potential failure points in sustaining continuous process improvement across the air force. Alabama: Air command and staff college, Air University.

Malheiros, V., Paim, F. R., \& Mendonca, M. (2008). Continuous Process Improvement at a Large Software Organization. Software Process Improvement and Practice, 14: 65-83. http://dx.doi.org/10.1002/spip.376

Nonthaleerak, P., \& Hendry, L. C. (2006). Six Sigma: literature review and key future research areas. Six Sigma and Competitive Advantage, 2(2):105-161. http://dx.doi.org/10.1504/JJSSCA.2006.010111

Person, D. (2007). Continuous process improvement within DOD. Defense AT\&L, 31-33.

Plamer, L. A., \& Ingrassia, B. C. (2005). Utilizing the Power of Continuous Process Improvement in Technical Services. Journal of hospital librarianship, 5(3): 93-98. http://dx.doi.org/10.1300/J186v05n03_09

Pojasek, R. B. (2003). Lean, six sigma, and the systems approach: Management initiatives for process improvement. Environmental Quality Management, 13(2): 85-92. http://dx.doi.org/10.1002/tqem.10113

Roger H., Margaret B., \& Amrik S. S. (2008). Factor critical to the success of a Six-sigma quality program in an Australian hospital. Total Quality Management, 19(9): 887-902. http://dx.doi.org/10.1080/14783360802224396

SBTI team. (2009). Who understand our customers, who will win the market! [Online] Available: http://www.sbtionline.com.cn/Consult_finance13.aspx

Shleifer, A., \& Vishny, R. W. (2009). Unstable banking. Journal of Financial Economics, 1-13.

Snee, R. D. (2010). Lean Six Sigma - getting better all the time. International Journal of Lean Six Sigma, 1(1): 9-29. http://dx.doi.org/10.1108/20401461011033130

Starks, G. L. (2009). Contracting excellence via Continuous process improvement. Defense AT\&L, 30-33.

Sterman, J. D., Repenning, N. P., \& Kofman, F. (1997). Unanticipated Side Effects of Successful Quality Programs: Exploring a Paradox of Organizational Improvement. Management Science, 43(4, Frontier Research in Manufacturing and Logistics): 503-521.

Vance, D. E. (2009). Reengineering, Process Mapping, Continuous process Improvement and Outstanding. Corporate restructuring, 151-167.

Wadsworth, H. M., Stephens, K. S., \& Godfrey, B. (2001). Modern Methods for Quality Control and Improvement. ( $2^{\text {nd }}$ edit.). New York: John Wiley \& Sons.

Ward, J. A. (1994). Continuous process improvement. Information System Management, 11(2): 74-76. http://dx.doi.org/10.1080/10580539408964640

Womack, J. P., \& Jones, D. T. (1996). Lean Thinking. New York: Free Press, Simon \& Schuster, Inc.

World Bank. (2008). World Development Indicators. [Online] Available: http://www.worldbank.org/DATASTATISTICS /Resources/WDI08_section4_intro.pdf

Yuan, Y., Dong, X., \& Lv, X. (2008). Innovations in Trade Financing Process of Commercial Bank. International Business research, 1(4):27-31.

Zineldin, M., \& Bredenlow, T. (2003). Strategic alliance: Synergies and challenges. International Journal of Physical Distribution \& Logistics Management, 33(5):449-464. http://dx.doi.org/10.1108/09600030310482004

$\mathrm{Zu}, \mathrm{X}$., Frederdall, L. D., \& Douglas, T. J. (2008). The evolving theory of quality management: The role of Six Sigma. Journal of Operations Management, 26(5): 630-650. http://dx.doi.org/10.1016/j.jom.2008.02.001 
Table 1. Service data comparison table of before and after improvement

\begin{tabular}{|c|c|c|c|}
\hline \multirow{3}{*}{ Project } & \multicolumn{3}{|c|}{ Data } \\
\hline & \multicolumn{2}{|c|}{ Before improvement } & \multirow{2}{*}{$\begin{array}{c}\text { After } \\
\text { improvement }\end{array}$} \\
\hline & 4 windows & 5 windows & \\
\hline Probability of no customer in system $\left(P_{0}\right)$ & $p_{0}=0.057$ & $p_{0}=0.229$ & $p_{0}=0.451$ \\
\hline Average number of queue customer( $L_{q}$, person $)$ & $L_{q}=15.557$ & $L_{q}=2.604$ & $L_{q}=0.672$ \\
\hline Average number of customer in system( $L_{s}$,person $)$ & $L_{s}=16.500$ & $L_{s}=2.832$ & $L_{s}=1.222$ \\
\hline Average queue time of every customer( $W_{q}$, hour) & $W_{q}=0.471$ & $W_{q}=0.096$ & $W_{q}=0.020$ \\
\hline Average stayed time every customer $\left(W_{s}\right.$, hour) & $W_{s}=0.500$ & $W_{s}=0.125$ & $W_{s}=0.037$ \\
\hline $\begin{array}{l}\text { Probability of customer who must to wait to queue when } \\
\qquad \text { arrived } \operatorname{system}\left(P_{w}\right)\end{array}$ & $p_{w}=0.943$ & $p_{w}=0.771$ & $p_{w}=0.550$ \\
\hline Probability of at least 7 customer in $\operatorname{system}\left(P_{s}\right)$ & $P_{s}=0.663$ & $P_{s}=0.163$ & $P_{s}=0.0149$ \\
\hline
\end{tabular}

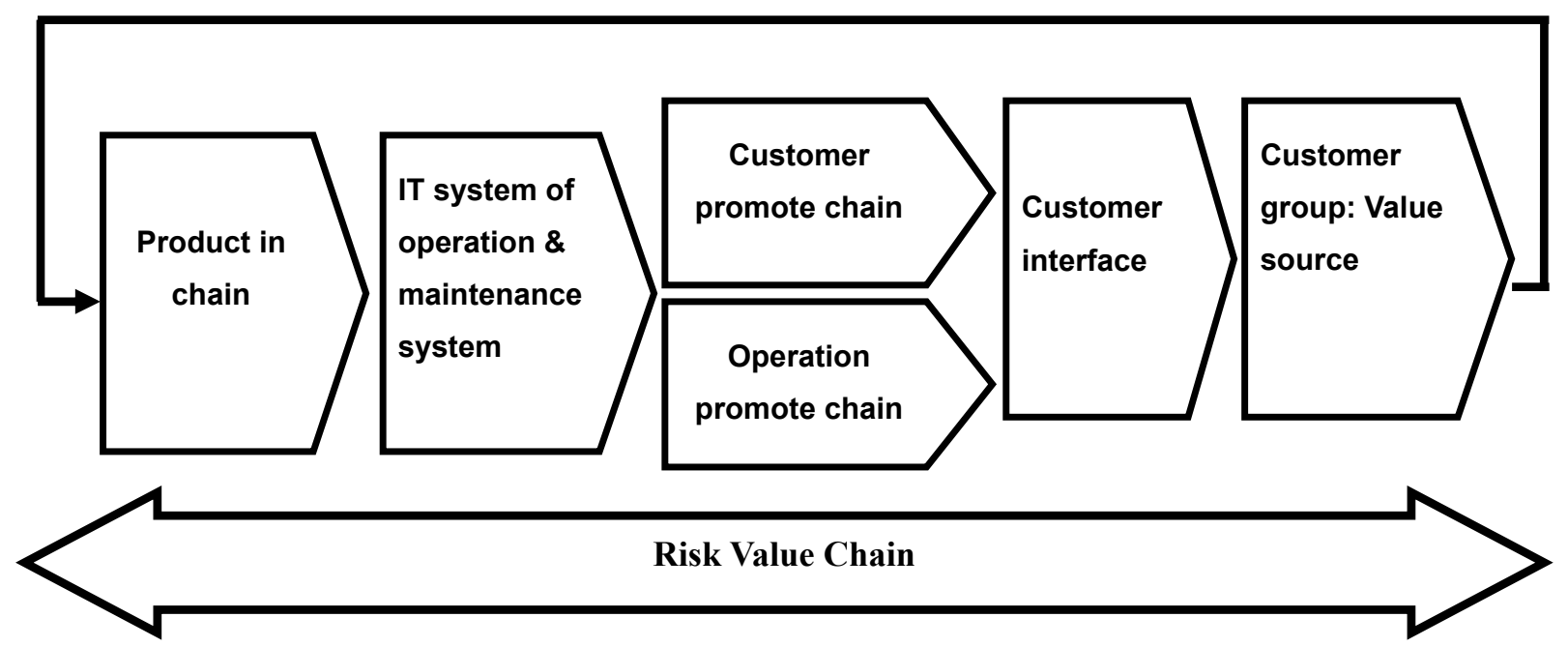

Figure 1. Processing bank system value chain based on LSS management 


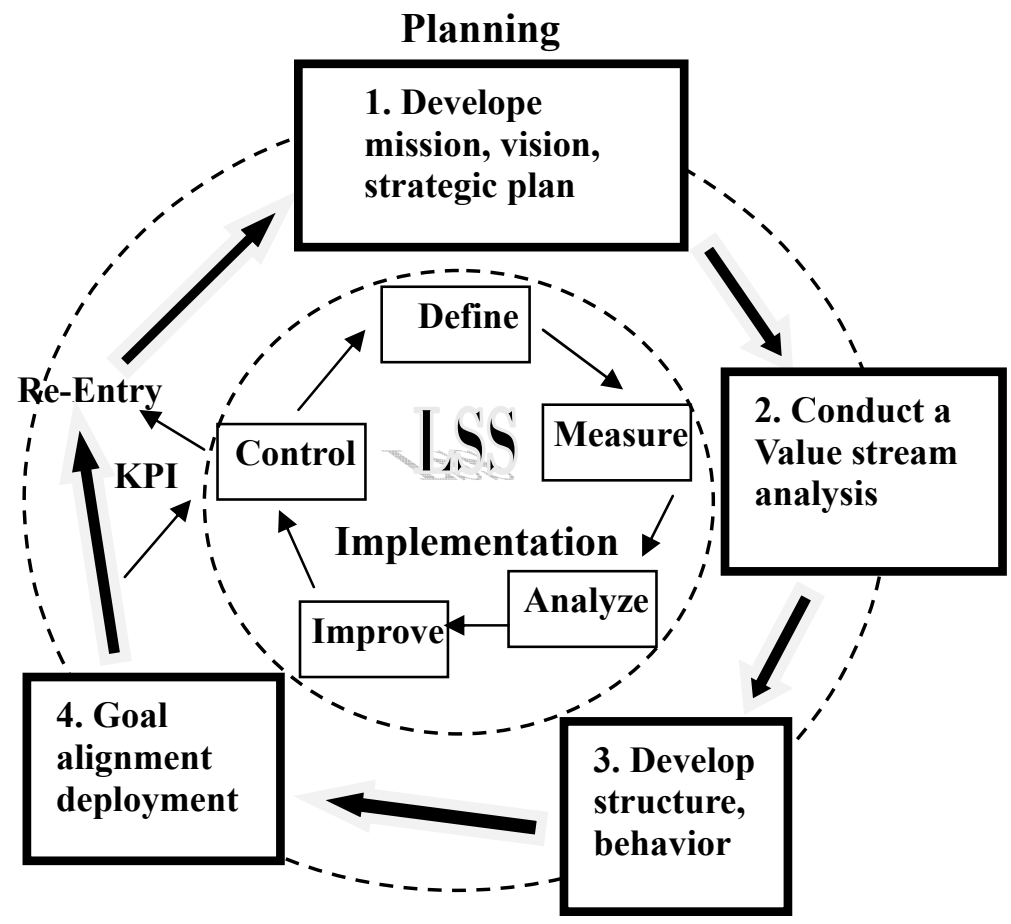

Figure 2. CPI--PBS Hybrid Deployment Model

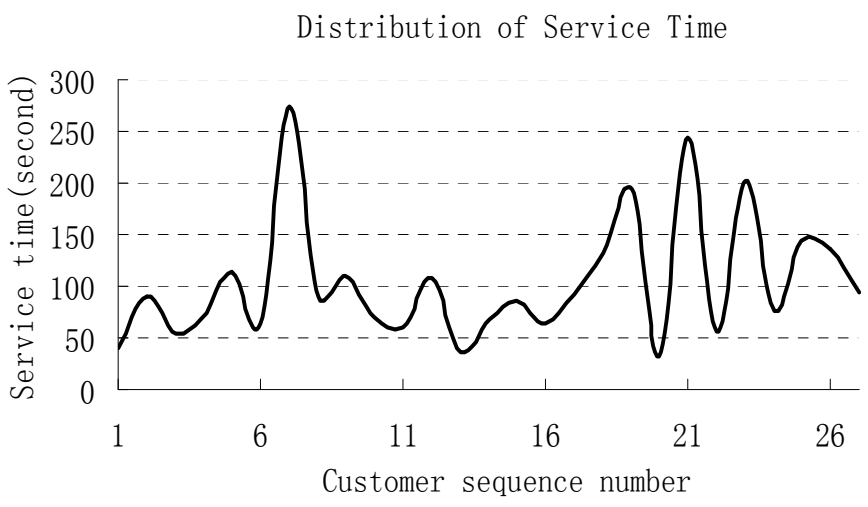

Figure 3. Distribution of Service Time

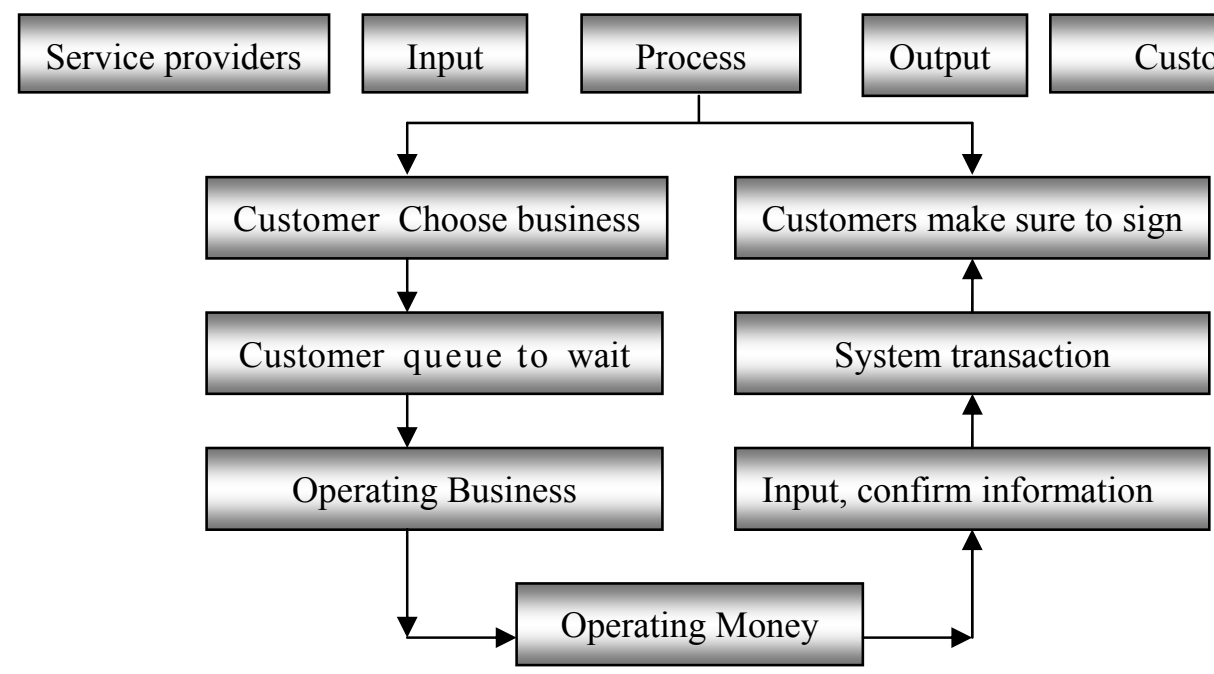

Figure 4. SIPOC Diagram of Bank Service System 